\title{
EL PROFESOR ANTE LOS MODELOS CULTURALES DE LA SOCIEDAD CONTEMPORÁNEA
}

\section{THE TEACHER WITH REGARD TO CULTURAL MODELS OF THE CONTEMPORARY SOCIETY}

\section{JULIO VERA VILA}

Universidad de Málaga. Departamento de Teoría e Historia de la Educación. Facultad de Ciencias de la Educación. Campus de Teatinos, 29071 Málaga.

\section{RESUMEN}

La institución escolar establece un sistema educacional que está culturalmente determinado y que consolida otras agencias de socialización tan importantes como los medios de comunicación de meses. En este trabajo se analizan algunos de los efectos de la televisión en cuanto es influenciada por estilos publicitarios y en cuanto que es un instrumento con propósito educativos que orienta el trabajo de los profesores.

\section{SUMMARY}

The scholar institution establishes an educational system that is culturally determinated, and that establishes other socialization agencias as important as massmedia. In this work it's analyzed some of the effects configuratives of an television each time it's more influenced by publicity-fashion styles, and each time it's more away from educational purposes that orientates the teacher's work. 


\section{LOS AGENTES CONFORMADORES DE LA PERSONALIDAD. LAS DISTINTAS INFLUENCIAS EDUCATIVAS.}

Todas las especies animales han de resolver el problema de la supervivencia antes que ningún otro, y para ello, han tenido que ser capaces de adaptarse a su medio. En el hombre este proceso de adaptación se produce a través de la sustitución progresiva de la reacción instintiva por un repertorio de respuestas, en principio pensadas por otros, que se han mostrado útiles para resolver necesidades o satisfacer deseos. A este proceso de aprendizaje de significados compartidos lo denominamos socialización y en él hay implicados procesos de educación informal, no formal y formal que sobrepasando las funciones adaptativas iniciales abren la posibilidad del cambio personal y social.

La institución escolar, con ser quizás la más importantes de todas las agencias educativas, no es sino uno más de los mecanismos conformadores de la personalidad en el seno de una sociedad. La familia, los amigos, el ámbito laboral, la iglesia, los partidos políticos, los sindicatos, las asociaciones y los medios de comunicación social, son otros tantos agentes de influencia que de una forma directa o indirecta, expresa o implícita, mayor o menor, contribuyen a determinar la forma en la que las personas se comportan, piensan o sienten.

Como además en las sociedades abiertas hay siempre un lugar para la discrepancia, nunca llega a alcanzarse un consenso generalizado acerca de los mensajes y los modelos de comportamiento que han de divulgar y defender todos esos dispositivos sociales con incidencia educativa, de manera que los valores y modelos cuya defensa se le encomienda a la escuela no siempre coinciden con los inculcados por la familia y, con demasaida frecuencia, están en abierta contradicción con los reforzados por los medios de comunicación social.

La coexistencia de modelos culturales divergentes, junto con la confusión axiológica, el cambio acelerado y la complejidad creciente de la vida social hacen que muchos educadores (padres y profesores) se sientan aturdidos y desconcertados, sin patrones claros de referencia a los que acudir. Como dice Mandra (1984, p. 216): «(...) la mayoría de las sociedades occidentales contemporáneas, no saben muy bien cual es su proyecto de realización. ¿Para qué destino colectivo trabaja la escuela? ¿Para qué futuro preciso? Sin respueta clara a tales preguntas, los interrogantes son más numerosos que las certidumbres y la coherencia del acto educativo se esfuma".

El momento presente es una de esas etapas históricas en las que prevalece la complejidad sobre la simplicidad, el cambio sobre la permanencia y la diversidad sobre la uniformidad, lo que engendra una grado mayor o menor de desfase bumano, concepto con el que se quiere expresar la distancia que media entre la creciente complejidad de la realidad y el retraso en el desarrollo de nuestra capacidades para hacerle frente (Botkin, J. W.; Elmandjra, M. y Malitza, M., 1979, p. 28). En este sentido, el crecimiento vertiginoso de los medios de comunicación y todas las nuevas tecnologías de la información no se ha visto compensado con un incremento paralelo de las capacidades codificadoras, descodificadoras, organizativas o de gestión que habilitan a las personas para su empleo consciente, por lo que éste 
es uno de los ámbitos culturales cuyo auge está generando mayor desfase humano entre la población.

Los medios de comunicación social y las nuevas tecnologías han de ser siempre bienvenidas como herramientas poderosas al servicio de la codificación, elaboración, gestión e intercambio de experiencias humanas, por lo que desde un punto de vista pedagógico interesa demandar su generalización como dispositivos útiles y eficaces de educación. Pero una vez subrayada su importancia como hardware susceptible de aplicación en múltiples modelos educativos, tanto en la escuela como fuera de ella, debemos también concentrarnos en el impacto configurador que realmente están teniendo, especialmente la televisión y el sistema publicidad/ moda, en la población general como consecuencia del desfase existente entre su enorme potencial tecnológico y la pobreza cultural no sólo de sus mensajes sino del uso que se les da. Véanse si no la instantaneidad con la que las viejas y nuevas tecnologías son aplicadas al ocio ensimismante y la demora con la que son empleadas con fines educativos.

Televisión y sistema publicidad/moda son, desde esta perspectiva, los dispositivos configuradores más potentes en la tarea de creación, difusión y refuerzo de unos modelos culturales de tipo simbólico en abierta contradicción con los modelos y valores promovidos por la institución escolar así como con su estilo transmisor. Ahora bien, la toma de conciencia del entorno cultural en el que circulan modelos y mensajes culturales contradictorios, ha de servir para que la institución escolar promueva la alfabetización audiovisual necesaria para que los medios sean reconsiderados como instrumentos de expresión y comunicación de una vida interior rica. El desfase humano creado por el acelerado crecimiento del poder persuasor de los medios no puede ser compensado pidiendo una utópica desaparición o censura de los mismos, sino reivindicando y desarrollando las tecnologías del crecimiento personal, es decir, revalorizando dentro del sistema estimativo público y privado el valor del aprendizaje educativo.

\section{El APRENDIZAJE DE MODELOS.}

Si tuviéramos que adquirir todo el conocimiento necesario para la vida actual por experiencia directa todos tendríamos un acusado retraso en nuestro desarrollo, debido a lo lento y penoso que resulta avanzar por el método de ensayo y error. Afortunadamente adquirimos muchos de los aprendizajes observando el comportamiento de los demás y las consecuencias que tales actuaciones les reportan, de manera que la influencia de un modelo puede modificar, de forma simultánea, la conducta, los patrones de pensamiento, las respuestas emocionales y las evaluaciones del sujeto observador (Bandura, 1987, p. 69).

El aprendizaje a través de modelos se ha comprobado que puede tener los siguientes efectos (Ibid, pp. 70-71):

a) Efecto inhibidor/desinhibidor de una condcuta previamente aprendida sobre la que pesa algún tipo de censura psicológica o social. Ello depende- 
rá de las consecuencias positivas o negativas que el modelo obtenga de ella y de si el sujeto se percibe capaz de realizarla con los mismos resultados. Por ejemplo conductas agresivas, comportamientos reprimidos o que han de vencer todavía ciertas barreras psicológicas antes de pasar a ser parte activa del yo, comportamientos transgresores de alguna vigencia social, etc.

b) Efecto inductor de respuestas previamente aprendidas que hasta ese momento habían estado latentes por falta de motivaciones suficientes. Es decir, que los modelos que prevalecen en un medio social determinan en parte las cualidades que serán activadas de forma selectiva, de entre todas las posibles a elegir. Por ejemplo un modelo puede inducir por igual al esfuerzo que a la pereza, al hábito reflexivo que al trato rutinario o poco consciente con la realidad.

c) Efecto de incremento de la estimulación ambiental al dirigir la atención del observador hacia elementos de su entorno o acciones que habían pasado desapercibidos para él, aunque les asigne otra finalidad o significado. Una riqueza de modelos ayuda al sujeto a interesarse por nuevos ámbitos de la realidad que podrá emplear en la construcción de su propio proyecto personal o que, por el contrario, le distraerán de la realización de objetivos valiosos.

d) Efectos de activación emocional al ver cómo los modelos expresan respuestas emocionales en asociación con ciertas personas, cosas, lugares o situaciones. La vía emocional representa una manera sencilla y rápida de valorar realidades que pueden llegar a ser muy complejas. Antes de llegar a construir un significado racional, las cosas gustan o disgustan según sean enseñanadas por los modelos de referencia, que de este modo adquieren un poder del que se hacen responsables. El profesor de matemáticas no sólo enseña su materia sino un modo, el que sea, de relación afectiva con ella.

Los modelados pueden ser fundamentalmente de tres tipos atendiendo al medio a través del cual se transmite la información:

a) Modelado por demostración física en directo (conductual). Es lo habitual en niños pequeños que no tienen competencia lingüística.

b) Modelado verbal que puede sustituir o complementar al modelado conductual.

c) Modelado simbólico que es aquel que emplea medios como el cine, la televisión, el vídeo, el ordenador, etc.

Las personas con las que uno interactúa de forma habitual delimitan los modelos de comportamiento que se observarán de forma repetida y que, por lo tanto, tendrán más posibilidades de ser aprendidos. Puesto que el sujeto tiene contacto directo sólo con un reducido número de personas, sus conceptos sobre la realidad social están influidos en gran medida por las experiencias vicarias de los medios de comunicación. 
JULIO VERA VILA

\section{LA EMERGENCIA DEL SISTEMA PUBLICIDAD/MODA COMO PRODUCTOR DE MODELOS CULTURALES EN LOS MEDIOS DE COMUNICACIÓN}

De entre todos estos agentes con influencias educativas el sistema publici$\mathrm{dad} /$ moda es de los más eficaces, ya que proporcionalmente ninguna educación formalizada invierte una cantidad de medios tan elevados como lo hace el sistema publicidad en estudiar al ser humano para lograr motivar a los receptores en su discurso. Todos los avances tecnológicos han sido aplicados al marketing y cada día aparecen nuevos entretenimientos tecnificados puestos al servicio de un modelo cultural que está en abierta contradicción con el que representa el sistema escolar.

Para algunos autores es la propia naturaleza de la televisión y de los demás medios de comunicación, la causa de la baja calidad de sus contenidos (Massó, 1993, p. 158). Para otros, su escaso valor educativo actual se debe a que han adoptado el discurso publicidad/moda, de mucha calidad técnica en las formas, pero con poco contenido, y ello por varias razones:

a) Necesita financiarse y ser rentable.

b) Su cliente fundamental no es el espectador sino el anunciante que paga para que se emitan sus anuncios.

c) El espectador es necesario como parte de la audiencia que hace rentable la publicidad.

d) Para incrementar los índices de audiencia necesita venderse a sí misma.

e) Para mantener la audiencia se va impregando de los recursos expresivos y de las técnicas motivacionales de la publicidad.

Los niveles de aceptación entre el público son los que determinan finalmente la programación, pero hay que reconocer una influencia mutua debido a que la audiencia acaba aprendiendo a disfrutar de aquello que se le refuerza incesantemente. Por estas razones, es decir, por la necesidad de ser comercial es por lo que la televisión acaba banalizándose como medio de comunicación y como contenido, frustrando de esta manera su enorme potencial educativo y difundiendo modelos culturales antagonistas de los inducidos desde la escuela.

El sistema publicitario es un conjunto de elementos personales, materiales, técnicos, etc., entre los que me interesa destacar las técnicas de persuasión, orientados todos ellos a incrementar las ventas.

Un publicista famoso decía lo siguiente a finales de los cincuenta: "Las mujeres pagan dos dólares y medio por una crema para el cutis, pero no más de veinticinco centavos por una pastilla de jabón. ¿Por qué? porque el jabón sólo les promete dejarlas limpias y la crema les promete bellezan (Cf. Ferrés, 1994, p. 153).

Es decir, que la publicidad inteligente primero ofrece ideales, valores y esperanzas, y después los productos adecuados, aunque como todos sabemos en muchas ocasiones los objetos no pueden satisfacer los deseos que ella misma crea. Por ejemplo, el tabaco no da virilidad, ni salud, ni alegría, a pesar de lo que dicen algunos anuncios.

En la misma línea se manifestaba un famoso editor de noticiarios al explicar la fórmula para el éxito: "Que todo sea breve, que no se fuerce la atención de nadie, 
sino que se de estimulación constante con variedad, acción y movimiento. (...) Hay que evitar la complejidad, los matices no son necesarios" (Cfr. Ibid., p. 46).

El sistema de moda por su parte ha venido a ocupar en la era del consumo el puesto de los referentes clásicos que representaban los modelos de comportamiento admitidos socialmente: La iglesia, la familia, el estado, la escuela, los partidos políticos, etc. Ella representa por su lógica interna la promoción de lo nuevo y la caducidad de las formas, la legitimación de todos los estilos de vida y al mismo tiempo su transitoriedad, el gusto del cambio por el cambio.

Ambas, publicidad y moda, resultan ser unos eficaces mecanismos de adaptación a una sociedad cuyo sistema económico se basa en el consumo. Publicidad, moda y consumo componen lo que Lipovetsky (1993) considera una forma de control flexible que funciona por seducción y que da lugar a un hombre indiferente, que no se aferra a nada por mucho tiempo, que no tiene certezas absolutas y cuyas opiniones son susceptibles de modificaciones rápidas (pp. 34-45).

A diferencia de otros modelos culturales que son considerados coactivos, la publicidad es libertina, desinhibida, divertida y seductora. Lanza mensajes pero, aparentemente, ni obliga ni vigila. $\mathrm{Y}$ sin embargo predice científicamente el porcentaje de gente que va a obedecer y controla el comportamiento posterior de forma imperceptible, es decir, sin molestar. Apela constantemente a la libertad, pero al gestionar científicamente la opinión pública crea vigencias sociales con el mismo poder coercitivo a escala planetaria que el cura o el alcalde tenía en las aldeas. Sus efectos alcanzan a mucha gente de forma casi inconsciente, sin dejar huella en la memoria, debido a una fugacidad de contenido que adquiere solidez en la forma. Lo efímero, lo ligero, lo divertido, lo intrascendente son características del núcleo duro y consistente de la propia esencia del mensaje moda.

Son quizás los rasgos incipientes de un cambio antropológico que implica un proceso de adaptación a una nueva cultura cambiante, tecnológica, internacional, virtual, consumista.

\section{Hábitos de consumo televisivo en Hedonía Datos de audiencia.}

El consumo televisivo actual hay que situarlo en el contexto de una cultura hedonista en la que el ocio se ha convetido en un derecho cívico, un hecho de relevancia política y un elemento económico de primera magnitud, tanto por el volumen de negocio que genera como por los sectores que moviliza en la esfera del consumo.

Según el informe Foessa (Juárez, M., 1994) los europeos dedican cada vez más tiempo y dinero a sus actividades de ocio, un ocio considerado como un fin en sí mismo que además de las funciones terapéuticas o reparadoras del esfuerzo, colma la aspiración a las satisfacciones placenteras y a la excitación emocional. Tres dinámicas cooperan simultáneamente en la misma dirección: el alargamiento escolar que implica un retroceso en la edad de entrada al trabajo; la elevación de la esperanza de vida, y la reducción de la jornada laboral junto a las demás transformaciones del mercado laboral. 
En todos los países europeos, la televisión ocupa el primer puesto entre las actividades de ocio, tanto por el tiempo que se le dedica, como por su universalización a todas las capas sociales. Los españoles y los portugueses, con un promedio de tres horas y media diarias, son los que más tiempo le dedican, frente a los holandeses y alemanes que no llegan a las tres horas de promedio (Ibid, p. 1907).

El mismo informe Foessa recoge datos de un estudio realizado conjuntamente por RTVE y el CIS en 1987 en el que se afirma que la televisión "se revelaba como la actividad de ocio, e incluso como la actividad a secas a la que los españoles dedicaban más tiempo. Para el 52\% de los encuestados se trataba del primer medio de entretenimiento y para el $77 \%$ de uno de los primeros: (Juárez, M., 1994, p. 2181), para concluir que la televisión se sitúa por encima de los demás medios de comunicación como difusor de cultura incluidos los libros, a lo que habría que agregar que se impone como vehículo de información y como modelo de una determinada cultura.

Según la encuesta del Centro de Investigaciones sobre la Realidad Social (CIRES, 1993), los hogares españoles tienen un buen equipamiento audiovisual que potencialmente les abre al intercambio de información con la realidad exterior aunque sea a través de modelos y experiencias vicarias, pero que realmente no despierta demandas educativas de calidad, sino más bien todo lo contrario. Un 98\% de los hogares españoles dispone de televisor en color, de éstos un 31\% cuenta con dos o más aparatos, un $81 \%$ tiene radiocassette, el $64 \%$ mando a distancia, el 54\% magnetoscopio, el 13\% ordenador personal, el $9 \%$ videocámara, el 2\% videotexto y el $1 \%$ modem y telefax.

Por contra, el $40 \%$ de los españoles no lee un libro nunca y el $84 \%$ no visita jamás una biblioteca, el 20\% no tienen ningún libro en su casa. La mayor parte de los libros leídos pertenecen al género de ficción, novelas y cuentos. El 74\% de los entrevistados por el CIRES no había leído nunca un libro técnico y casi lo mismo pasa con la poesía o el teatro, géneros no leídos por tres cuartas partes de los españoles. En la misma línea de marginación se encuentra el mundo artístico si tenemos en cuenta que a pesar de contar con museos de renombre internacional, la visita a éstos es todavía casi testimonial. Más del $80 \%$ de los españoles no gustan de visitar museos y exposiciones, si bien aumenta su afición por los viajes y por los juegos de toda índole, tanto los que fomentan la convivencia, como los de apuesta que en 1987 movilizaron dos billones y medios de pesetas. (Cfr. Juárez, M., 1994 y CIRES 1993).

El análisis del porcentaje de españoles mayores de catorce años que se exponen regularmente a los diferentes medios de comunicación confirma la hegemonía de la televisión (Miguel, A. de, 1994, p. 685):

TV

Revistas semanales

Suplementos dominicales de diarios

Radio

Diarios

Revistas mensuales
$89 \%$

$48 \%$

$37 \%$

$36 \%$

$34 \%$

$27 \%$ 
Aunque la televisión como actividad de ocio no conoce diferencias de clase social, edad o sexo, sino que es la aldea global en la que se emplean tres horas y media diarias de media, sin apenas diferencia entre los diferentes entornos urbanos o rurales, no todos los españoles creen tener el mismo grado de dependencia de la televisión. Según Amando de Miguel (1994) al 38\% de los españoles les resulta difícil prescindir de la televisión, es decir, son teleadictos, y este fenómeno es mayor entre las personas de más edad, de menor nivel de estudios, y de clase social más humilde (pp. 366, 370 y 371).

Los datos de audiencia ponen de manifiesto, entre otras cosas, cómo la televisión ha supuesto una modificación en el uso del tiempo libre, puesto que ella misma surge en un momento en el que empieza a extenderse la idea del ocio, y también que la televisión representa un modelo de socialización que ha alterado enormemente el poder que antes tenían otros ámbitos porque no hemos aprendido a dirigirla.

Ha debilitado la eficacia de la familia porque ha invadido el espacio privado del hogar disminuyendo las comunicaciones interpersonales. En Estados Unidos se calcula que el tiempo que dedican los padres a conversar con los hijos no supera los quince minutos diarios, incluso los sábados y los domingos. Del mismo modo, en una encuesta realizada en once países occidentales ha mostrado que pocos padres son los que consiguen encontrarse a solas con su hijo más de cuarenta y cinco minutos al día. La mayor parte de las horas que pasan las familias reunidas corresponden a las que se sientan ante el televisor, y cuando hablan lo hacen, sobre todo, refiriéndose a la pantalla. Con los cambios que pueden suponer las nuevas tecnologías en el ámbito laboral y en el ocio, se espera que aumente el tiempo de permanencia en casa de todos los miembros de la familia, pero no sus comunicaciones directas. (El País, 25/2/95, p. 19).

Ha alterado el influjo socializador de los espacios urbanos como calles, plazas, parques y jardines, porque se hace menos vida social en ellos.

Finalmente contribuye a difundir unos modelos culturales contradictorios con el modelo que representa la escuela, amenazada como las demás instituciones por el discurso que representan la publicidad, la moda y el consumo. Al cabo del año y teniendo en cuenta que la TV se hace más en los fines de semana, se calcula que un niño de EGB al cabo del año ha estado más horas ante el televisor que en clase.

\section{EFECTOS CONFIGURATIVOS DE LOS MEDIOS DE COMUNICACIÓN (TELEVISIÓN).}

\subsection{Multiplicación de modelos simbólicos y experiencias vicarias.}

La televisión es capaz de transmitir un modelo de conducta a muchas personas en lugares muy distantes y ha aumentado el número de arquetipos a los que el sujeto tiene acceso, pues trasciende las fronteras de su vida social inmediata, acercándole a valores y estilos de conducta de otros segementos de la sociedad y de otras culturas. 
Este aumento de experiencias y de relaciones vicarias con personajes, héroes o protagonistas de la televisión, en muchas ocasiones se hace a costa de un debilitamiento de las experiencias y las relaciones sociales efectivas con sujetos de carne y hueso. En cualquier caso esos modelos le permiten al espectador ponerse en su lugar, identificarse o proyectar en ellos sus sentimientos, como también le pueden ayudar a situarse imaginativamente ante la realidad al disponer de un repertorio plural de tipo.

$\mathrm{Al}$ aumentar el número de experiencias vicarias el período de la infancia tal y como lo conocíamos tiende a acortarse, en el sentido de que anticipa respuestas a sucesos modelantes que antes se desencadenaban por demandas de la vivencia directa, pero sin lograr un desarrollo formativo sólido, justo en un momento en el que las expectativas de vida permitirían no tener tanta prisa por quemar etapas.

Las nuevas tecnologías en el futuro inmediato van a incrementar exponencialmente el acceso de muchas personas a modelos de cualquier actividad que desee, con la limitación insoslayable de la propiedad restringida de los bancos de datos, programas e informaciones y el sistema deacceso a ellos. La primera es una limitación ideológica, la segunda económica.

\subsection{Contribuyen a bacernos la imagen de la realidad.}

Hoy en día nuestra imagen la realidad está construida básicamente por los medios de comunicación gracias a que:

a) la densidad de las imágenes en nuestro entorno es tan grande que constituyen un ambiente cuya influencia pasa desapercibida por su cotidianidad. Esto significa que cada vez aumentan las experiencias vicarias con los modelos virtuales y decrecen las experiencias directas.

b) Contribuyen a crear también los conceptos y las categorías con los que pensamos y clasificamos la realidad. Por ejemplo han alterado la forma en la que entendemos el tiempo y el espacio, pero también los criterios con los que juzgamos lo bueno o lo malo, lo bello y lo feo.

c) Cada vez hay una mayor identificación entre lo que se considera real, existente y lo que aparece publicitado en los medios, de manera que lo que no aparece permanece desconocido e ignorado, como si no existiese. Una prueba de ello es la forma en que la política se ve obligada a atender los asuntos en el orden que marca la actualidad.

d) La televisión y, en general, la imagen tiene una credibilidad muy superior a la de otros medios como confirma la expresión "lo he visto con mis propios ojos". La imagen televisada sobre todo si es en directo produce efecto realidad e ilusión de verosimilitud, parece como si la cámara reprodujera la realidad tal como es, de una forma transparente, como si no hubiera mediación. El efecto es mucho menor en un texto escrito porque se sabe que ha sido construido por una persona: selección, organización, interpretación, etc.

e) Las imágenes aparentemente son accesibles a todos porque permiten niveles de interpretación en los que no hacen falta competencias ni aprendizajes previos. 
Mientras que es imposible leer un libro sin haber invertido muchas horas en adquirir un nivel de competencia suficiente, la imagen permite descodificacines muy rápidas. Su elevado grado de iconicidad permite ser interpretada como un trozo de realidad olvidando su carácter mediador de mensajes, que se descubre fácilmente en las imágenes que equívocamente llamamos abstractas, puesto que todas lo son.

f) Debido al enorme atractivo de la imagen, la realidad cotidiana puede parecer aburrida y decepcionante, por lo que en cierto sentido puede ser cierto que hoy en día es la realidad la que imita a la imagen, o lo que es lo mismo, que la realidad se evade de sí misma. El desarrollo tecnológico ha permitido, a las personas capacitadas en el dominio de los códigos icónicos, la invención de realidades tan sugerentes, que la capacidad de ensoñación del ser humano puede convertirla fácilmente en una forma de evasión falsamente superadora de la realidad. La imagen, en todo caso, como herramienta que es, permite representar una realidad desprovista de aquellos matices desagradables que nos encaran a nuestras responsabilidades y esto es lo que hasta ahora ha hecho el sistema publicidad/moda.

Sin embargo, bajo la apariencia de objetividad y realismo, la imagen tiene recursos técnicos para desvirtuar la realidad, por ejemplo, a través de los estereotipos que contribuye a crear del hombre, de la mujer, de los adultos, de los niños, de las minorías culturales, etc. En este sentido, los medios de comunicación son tan capaces de castigar ciertas diferencias (obesidad, calvicie, etc.) como de contribuir a integrar a los marginados y a hacer una sociedad más humana y pluralista. En cualquier caso, esta capacidad de la imagen sólo es un problema cuando por no saber leer imágenes en el contexto histórico-cultural en el que se dan, se les otorga una objetividad que no tienen.

Los niños son especialmente vulnerables por su incapacidad para distinguir entre imagen y realidad. Pero también los adultos confunden en ocasiones imagen y realidad, como demuestran los casos de agresiones a actores o actrices que encarnan un personaje perverso de alguna serie. O personas que escriben a las emisoras porque se han enamorado de un personaje.

El hecho de que hoy en día nuestra imagen de la realidad esté construida básicamente por los medios de comunicación es preocupante porque como indica Ferrés (1994):

a) Las informaciones mundiales están por cuatro grandes agencias: Associated Press, United Press International (USA), Reuters (británica) y France Press (francesa).

b) E1 79\% de los derechos de programas de TV que se venden en el mundo pertenecen a un sólo país, es decir, provienen de un sólo modelo cultural (USA).

\subsection{Cambian nuestros hábitos y estilos perceptivos.}

La televisión, que como ya dijimos va adoptando los estilos de la publicidad, transforma los hábitos perceptivos de los espetadores al crear la necesidad de una hiperestimulación sensorial. Para las nuevas generaciones los estilos narrativos len- 
JULIO VERA VILA

tos son aburridos porque están acostumbrados a mensajes con muchos cambios de plano, movimientos rápidos de la cámara, movimiento en el encuadre, etc. Esta cultura de la hiperestimulación sensorial choca con las características del aprendizaje escolar más reflexivo y sosegado.

Hay muchos datos que ilustran estos cambios en los hábitos perceptivos (Id):

a) La duración media de cada plano en las películas comerciales de los años 40 y 50 era de entre 12 y 15 segundos. En la actualidad, según diferentes investigaciones la duración media de un spot publicitario es de 1,5 segundos. En series japonesas de dibujos animados 3,5 segundos.

b) Según algunos estudios sólo una tercera parte del zapping se realiza para evitar la publicidad, en los demás casos es una forma de incrementar la estimulación sensorial a la que nos ha habituado el estilo publicitario de la TV. En USA y Francia uno de cada cuatro espectadores confiesa hacer zapping con frecuencia. Este fenómeno se da entre personas jóvenes y decrece con la edad.

c) Siguen apareciendo nuevas formas como el grazzing que consiste en el salto constante de canal para seguir varios programas a la vez.

d) Según investigaciones de USA, el $85 \%$ de los adolescentes son incapaces de leer sin fondo musical.

e) Mientras que una persona media del siglo XIX emitía un mensaje por cada 50 que recibía, un hombre medio de hoy en día por cada mensaje que emite recibe 50.000 . Lo que demuestra la unidireccionalidad de los medios y la falta de interactividad.

El exceso de mensajes y la consiguiente saturación receptiva impide que la información pueda ser digerida de forma significativa, sobre todo cuando se trata de estímulos inconexos, dispersos, contradictorios y difícilmente integrables en un todo significativo. De modo, que la televisión favorece un tipo de saber disperso, inconsistente, poco estructurado, pero enormemente atractivo y tendente a habituar a la sorpresa y a la gratificación sensorial constante.

En cuanto a la forma, el estilo publicitario se caracteriza por: mucha imagen, mucho titular, mucho slogan y poco contenido.

La necesdad de hiperestimulación sensorial inducida por la TV, la publicidad y otros medios, refleja en cierto modo el estilo de vida, el modelo cultural de nuestro tiempo en las sociedades del consumo: necesidad de ritmo frenético, escasa capacidad de concentración, necesidad de probarlo todo y cambiar frecuentemente de ambiente a través del viaje.

\subsection{Cambios en los procesos cognitivos.}

Cada medio de comunicación provoca diferencias en la forma de percibir la realidad y, en consecuencia, en los distintos procesos mentales que cada uno activa. Lo ideal, por lo tanto, es utilizarlos todos de forma complementaria.

Ahora bien, cualquier proceso cognitivo puede tener lugar con distintos niveles de profundidad: automático, sensitivo, consciente y creativo (Pérez Tornero, 1994, p. 38). Si comparamos los estilos cognitivos que desarrollan el texto escrito 
y las imágenes podemos hallar diferencias importantes, pero ambas pueden alcanzar el nivel creativo tanto en la lectura como en la escritura.

Me ceñiré a las diferencias más significativas desde el punto de vista educativo:

Texto escrito

Reflexivo, analítico, abastracto

Gratifica tras un esfuerzo

Paciencia, demora del placer

Más concentración

Esfuerzo descodificador a

cualquier nivel
Imagen

Intuitivo, global, asociativo, concreto Más implicación emotiva.

Menor control del ritmo de lectura. Gratificación instantánea. Impaciencia

Permite niveles de descodificación sin esfuerzo.

Salomón (Cfr. Bandura, 1987, p. 93) encontró que cuanto mayor es el esfuerzo cognitivo que invierte el individuo en extraer información importante y en elaborar su significado, mayor es el aprendizaje y el recuerdo de lo que ha sido presentado por uno u otro medio.

La conclusión es la siguiente: a igual cantidad de información, es preferible el medio percibido como más exigente puesto que movilizará una mayor cantidad de esfuerzo cognitivo. Por lo general los niños consideran las imágenes más fáciles y los escritos más difíciles.

Estas afirmaciones que son válidas con carácter general no son de aplicación a todas aquellas imágenes realizadas con el estilo publicitario y expuestas al sistema moda, porque ellas sí que producen una dificultad real de procesamiento consiciente.

\subsection{Dificultad de procesamiento consciente.}

Se conoce como efecto MacLuhan, (Cfr., Ferrés, 1994, pp. 96-97) a la sobrecarga perceptiva por estímulos transmitidos a un ritmo trepidante, muchos de los cuales pasan inadvertidos ante la imposibilidad material de procesarlos conscientemente.

Otra forma de burlar los controles racionales consiste en provocar asociaciones condicionadas de manera que el mensaje sea implícito. Por ejemplo algunas marcas de cigarrillos asocian su nombre al mundo del oeste americano para transmitir implícitamente la idea de salud, energía, vitalidad, etc.

Mediante experiencias de laboratorio se ha podido comprobar que la tensión emocional altera el umbral de reconocimiento de los estímulos reduciendo la posibilidad de una percepción reflexiva y crítica. Es sabido que la televisión moviliza mucha emotividad.

Para quienes han nacido en la era de la televisión y la publicidad, ambos representan un lenguaje natural, familiar, por lo que muchas veces pasa desaper- 
JULIO VERA VILA

cibida la enorme influencia que ejercen en nuestras vidas (Pérez Tornero, 1994, p. 125).

\subsection{Efectos emocionales.} formas:

El espectador participa emocionalmente con el modelo simbólico de dos

a) La identificación. Se produce cuando el espectador asume el papel de un personaje por considerarse reflejado en él.

b) La proyección se produce cuando el espectador descarga sus sentimientos en los personajes: amor, odio, compasión, deseo, alegría, tristeza, etc.

Son dos formas de participar de manera vicaria sin correr riesgos ni sufrir consecuencias. En ambos casos el sujeto aprende valores, actitudes, formas de afrontar los problemas, etc. de sus personajes y todo ello, de una forma poco crítica.

En general se puede afirmar que el sistema publicidad/moda tiende a provocar comportamientos y respuestas emotivas, por críticas, y escasamente perseverantes, por lo que una exposición prolongada ante los medios que lo canalizan es contraproducente para la necesaria persistencia en las tareas escolares.

\subsection{Teleadicción.}

Las investigaciones han descrito dos síndromes que afectan a los niños que ven un exceso de televisión.

a) El síndrome de teleadicción: fatiga, aburrimiento, falta de concentración, estado semi hipnótico, trastornos del sueño, etc.

b) El síndrome de reincorporación es similar a cuando se despierta de un sueño y tardamos en ser capaces de volver a la realidad (Ferrés, 1994, p. 113).

\section{UN CAMBIO ANTROPOLÓGICO. UN MODELO DE HOMBRE BANALIZADO.}

Desde mi punto de vista, el sistema formado por la publicidad, la moda y el consumo conforman un modelo cultural (una nueva forma de socialización) que está contribuyendo a un cambio antropológico, es decir a un nuevo tipo de personalidad humana adaptada a las necesidades de un sistema económico basado en el incremento del consumo inconsciente.

Según Lipovetsky (1993, pp. 18-24) el modelo de consumo se basa en la actualidad en ofrecer la elección libre y a la carta, es decir, en diversificar la oferta para que cada persona pueda seleccionar con libertad sus objetos de consumo. El consumo se diversifica y se individualiza, se personaliza e intensifica sus estrategias persuasivas impregnando de ideología moda a todo tipo de actividad.

Ello da lugar a un hombre indiferente que no se aferra a nada, que no tiene certezas absolutas y cuyas opiniones sufren modificaciones rápidas. Pocas perso- 
nas tienen creencias solidas en los valores que antes servían para darle un sentido a la vida, pero no importa porque el sistema sigue funcionando gracias a los valores de usar y tirar que no comprometen a nada y permiten un tono vital desenfadado.

El sujeto ante el bombardeo de mensajes nuevos y contradictorios, carente de referentes estables que organicen su personalidad, es un ser con una voluntad débil, en estado de pura disponibilidad, preparado para un reciclaje permanente.

El hombre actual desprovisto de certezas se caracteriza por su vulnerabilidad. Los jóvenes son los más afectados por estos nuevos modelos de socialización que desestructuran su personalidad. La contradicción va a surgir de forma inevitable entre un sistema que ofrece modelos eufóricos y la satisfacción de todos los deseos individuales y una realidad de paro y marginación. Muchos jóvenes son las principales víctimas del vacío existencial del nuevo narcisismo y se muestran cada vez más incapaces de afrontar la prueba de lo real. En USA el suicidio es ya la segunda causa de muerte entre los jóvenes después de los accidentes de coche (Ibid, pp. 212-213).

Estos cambios amenazan también la educación en la institución escolar, por ejemplo en los siguientes aspectos:

a) El descrédito y la desacralización de los agentes tradicionales de socialización ha afectado también a todo el cuerpo docente. La función docente está en crisis por falta de legitimación. Todos somos iguales ante la verdad porque todo es relativo.

b) Escepticismo ante el saber, la búsqueda de la verdad.

c) El esfuerzo ya no está de moda, su puesto ha sido ocupado por un concepto difuso de motivación. rante.

d) Atención dispersa de los alumnos interesada por todo pero poco perseve-

e) Los métodos educativos corren el riesgo de comercializarse.

f) Se corre el riesgo de movimientos involucionistas que quieran retroceder a modelos autoritarios.

\section{NECESIDAD DE RECUPERAR EL ORGULLO DE ENSEÑAR.}

La educación debería ser una especie de cirugía estética interior que periódicamente nos tensara la vitalidad para saber sentir, pensar y actuar más y mejor. Desgraciadamente es más cómoda y se valora más la cirugía de superficie, por ello los mensajes publicitarios insisten: ¡aprenda (Inglés) sin esfuerzo;, ¡coma cuanto quiera y pierda peso! La vida parece feliz, fácil y dichosa en la pseudorealidad creada por los dispositivos del sistema publicitario. En las aulas la voz menos potente de los profesores y profesoras invitan a sus alumnos al esfuerzo de aprender.

Es evidente que en la sociedad actual la pedagogía del esfuerzo, de la responsabilidad y del deber se está haciendo, cuando se hace, prácticamente a contra corriente del modelo de socialización dominante anteriormente analizado. 
Por todo ella la educación, especialmente en la familia y en la escuela, debe ser una invitación a la realización de un proyecto creador. La realidad sólo parece aburrida cuando todavía no hemos sido capaces de descubrirle el significado que la convierte en un elemento más de nuestro proyecto vital.

La educación es un proceso de permanente reajuste entre el yo actual y el yo proyectado que exige un esfuerzo sostenido, lo cual ni condena al sacrificio ni excluye el componente lúdico.

Debemos ayudar a los jóvenes a construirse un yo fuerte, apelando a valores como el esfuerzo, instándoles a buscar un sentido personal a valores como la dignidad, la verdad, la belleza. En este camino hay que incorporar como herramientas de enseñanza y aprendizaje todas las nuevas y viejas tecnologías que se pueda porque las diferentes formas de codificación/descodificación de la información movilizan más componentes cognitivos y afectivos que una sola aunque sea tan evolucinada como el lenguaje oral o el escrito.

Frente a los modelos culturales desprovistos de certezas, que se desentienden de la transmisión de valores y que sólo ofrecen modelos de identificación basados en la apariencia, huyendo de las utopías frustrantes, debemos recuperar el orgullo de ejercer un actividad al servicio de la comunidad (Esteve; Franco; y Vera, 1995). 
JULIO VERA VILA

EL PROFESOR ANTE LOS MODELOS CULTURALES DE LA SOCIEDAD CONTEMPORÁNEA

\section{BiBLIOGRAFÍA}

Alonso, M. y Otros (1986): Los teleniños. Laia, Barcelona.

Bandura, A. (1987): Pensamiento y acción. Fundamentos sociales. Martínez Roca, Barcelona.

Botkin, J. W.; ElmandjRa, M.; Malitza, M. (1979): Aprender horizonte sin limites. Santillana, Madrid.

CIRES (1993): La realidad social en España 1992-1993. Ediciones B. Madrid.

Colom, A.J. y MÈıICH, J-C. (1994): Después de la modernidad. Nuevas filosofías de la educación. Paidós, Barcelona.

Cueto, J. (1981): La sociedad de consumo de masas. Salvat, Barcelona.

De Fleur, M.L. y Ball-Rokeach, S.J. (1983): Teorías de la comunicación de masas. Paidós, Barcelona, $4^{\mathrm{a}}$ ed.

ECHEVERRía, J. (1994): Telépolis. Destino, Barcelona.

Esteve, J.M. (1983): La influencia de la publicidad en TV sobre los niños. Narcea, Madrid.

EsteVe, J.M.; Franco S. y Vera, J. (1995): El profesor ante el cambio social. Antrophos, Barcelona.

Ferrés, J. (1994): Televisión y educación. Cuadernos de Pedagogía/Paidós, Barcelona.

Gervilla, E. (1993): Posmodernidad y Educación. Valores y cultura de los jóvenes. Dykinson, Madrid.

GonZÁlez ReQuena, J. (1988): El discurso televisivo: espectáculo de la posmodernidad. Cátedra, Madrid.

JuÁREZ, M. (Dir) (1994): V Informe sociológico de la situación social en España. Fundación Foessa, Madrid.

KrasNy BRown, L. (1991): Cómo utilizar bien los medios de comunicación. Visor, Madrid.

Lipovetsky, G. (1990): El imperio de los efimero. La moda y su destino en las sociedades modernas. Anagrama, Barcelona.

LIPOVETSKY, G. (1993): La era del vacío. Ensayos sobre el individualismo contemporáneo. Anagrama, Barcelona. ( $6^{\mathrm{a}}$ ed. La $1^{\mathrm{a}}$ ed. en castellano es de 1986 y la francesa de 1983).

LIPOVETSKY, G. (1994): El crepúsculo del deber. La ética indolora de los nuevos tiempos democráticos. Anagrama, Barcelona.

MANDRA, R. (1984): “Causas de inadaptación y desadaptación de los enseñantes franceses y dispositivo de ayuda puesto en marcha por el Ministerio de Educación Nacional", en Esteve, J.M. (Ed). Profesores en conflicto. Narcea, Madrid.

Marías, J. (1972): La estructura social. Alianza, Madrid.

MARINA, J.A. (1992): Elogio y refutación del ingenio. Anagrama, Barcelona.

MARINA, J.A. (1993): Teoria de la inteligencia creadora. Anagrama, Barcelona, $2^{\mathrm{a}}$ ed.

MAssó, R. (1993): El éxito de la cultura light. Ronsel, Barcelona.

MigUel, A: DE (1994): La sociedad española 1994-1995. Universidad Complutense, Madrid.

ORTEGA y GASSET, J. (1976): Ideas y creencias. Espasa Calpe, Madrid, $8^{\text {a }}$ ed.

Ortega, P. y Martínez, Fco. (Coord) (1994): Educación y nuevas tecnologías. Cajamurcia, Murcia. 
Pérez Tornero, J.M. (1994): El desafio educativo de la televisión. Para comprender y usar el medio. Paidós, Barcelona.

Rico, L. (1992): Tv, fábrica de mentiras. Espasa, Barcelona.

ROJAS, E. (1992): El hombre light. Una vida sin valores. Temas de hoy, Madrid.

Sanagustín, P. y otros (1991): El sueño consumista. Consejería de Salud de la Junta de Andalucía.

SANVICENS, A. (1985): Educación y medios de comunicación social. En AA. VV. Condicionamientos sociopolíticos de la educación. Ceac, Barcelona.

Sarramona, J. y otros (1988): Medios de comunicación de masas y educación. En SarRamoNA, J. (Ed.): Comunicación y educación (pp. 136-157). Ceac, Barcelona.

Toffler, A. (1981): La tercera ola. Plaza y Janés, Barcelona, $4^{\mathrm{a}}$ ed.

Trilla, J. (1993): La educación fuera de la escuela. Ambitos no formales y educación social. Ariel, Barcelona.

VÁzquez, G. (1994): Tecnologías avanzados y educación. En CAstillejo, J.L. Y otros. Teoría de la Educación (pp. 303-323). Taurus Universitaria, Madrid.

VÁzquez, S. M. (1993): Rendimiento escolar y esfuerzo: hacia la revalorización de la autonomía personal en el proceso educativo. Revista Española de Pedagogia, 195, 227-250.

VILCHES, L. (1993): La televisión. Los efectos del bien y del mal. Paidós, Barcelona. 